See discussions, stats, and author profiles for this publication at: https://www.researchgate.net/publication/259749475

\title{
Rethinking Musical Instrument Classification: Towards a Modular Approach to the Hornbostel-Sachs System
}

Article in Yearbook for Traditional Music · January 2011

DOI: 10.5921/yeartradmusi.43.0122

CITATIONS

7

2 authors:

Stephanie Weisser

Université Libre de Bruxelles

30 PUBLICATIONS 106 CITATIONS

SEE PROFILE
READS

1,850

Maarten Quanten

Brussels University Association

2 PUBLICATIONS 7 CITATIONS

SEE PROFILE

Some of the authors of this publication are also working on these related projects: 


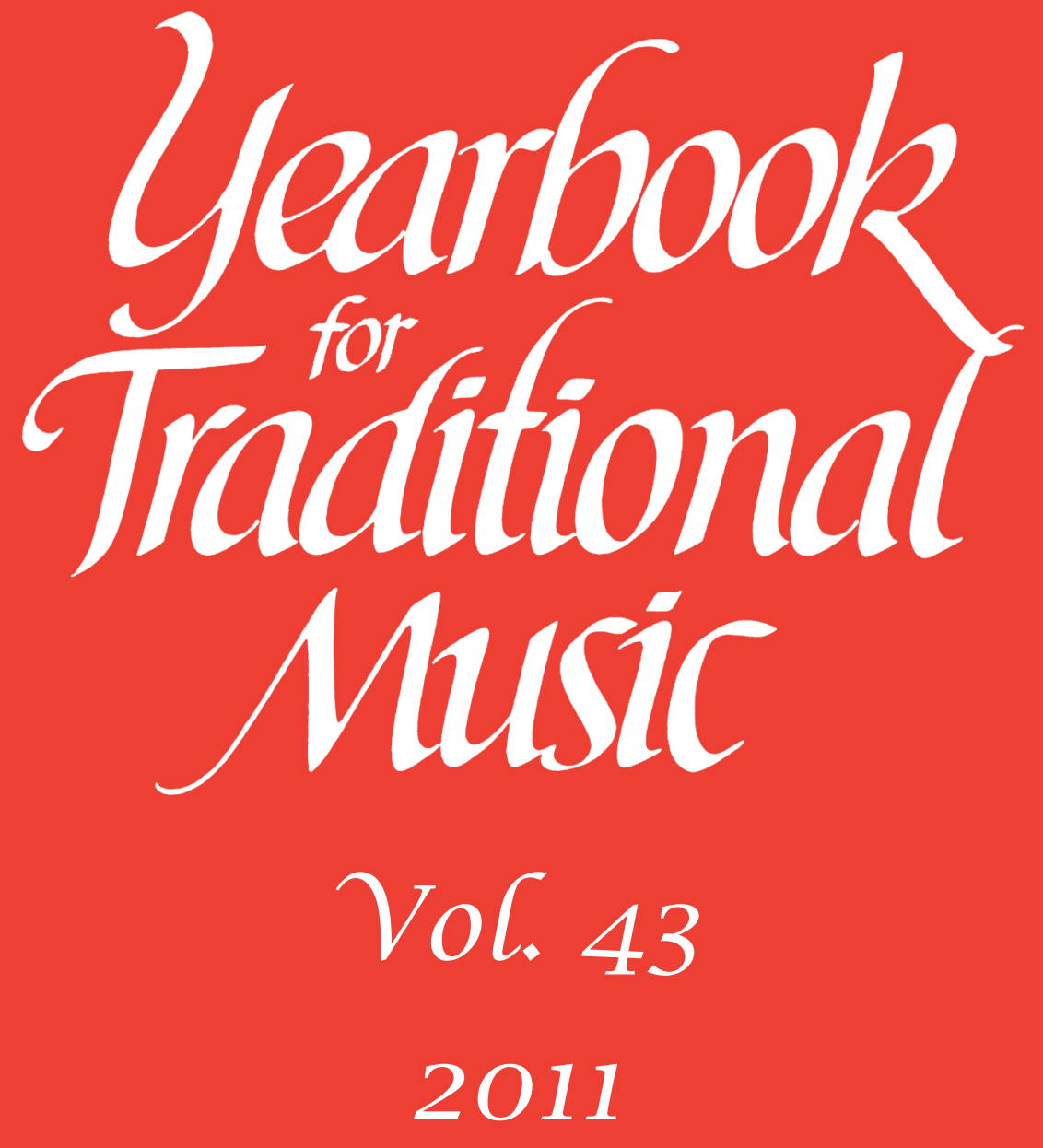





\title{
2011 YEARBOOK FOR TRADITIONAL MUSIC
}

Volume 43

\author{
DON NILES \\ General Editor \\ SYDNEY HUTCHINSON \\ Book Reviews \\ BYRON DUECK \\ Audio Reviews \\ LISA URKEVICH \\ Film/Video Reviews \\ BARBARA ALGE \\ Website Reviews
}




\title{
RETHINKING MUSICAL INSTRUMENT CLASSIFICATION: TOWARDS A MODULAR APPROACH TO THE HORNBOSTEL-SACHS SYSTEM
}

\author{
by Stéphanie Weisser and Maarten Quanten
}

\section{Preliminary thoughts: The Hornbostel and Sachs classification system in the era of computers and networks}

In 1914, Erich von Hornbostel and Curt Sachs created a hierarchic ordering (macrotaxonomy) of all musical instruments, even though they (and many others after them, see Kartomi 1990 and 2001) pointed out the difficulty of developing a systematic classification of all musical instruments (Hornbostel and Sachs 1961:5). This conceptual framework implies that the classifier has to walk one and only one route in the process of classifying objects. This cut-off "tracing" cannot possibly encompass all the possible features that make an instrument what it is and inevitably eliminates several other essential qualities of the object.

Almost one hundred years after its first publication, the Hornbostel-Sachs (H-S) system, still used by most musical instruments museums and in large inventory projects such as the MIMO, ${ }^{1}$ raises a lot of questions about its relevance: several instruments can simply not be accurately identified using the criterion of the "initial vibration." And what is to be done with organs and other hybrid designs? What is to be done with musical instruments that are not exclusively one, but two, or even many?

In this paper, we study the possibility of achieving a convenient and rather easyto-implement way to incorporate such instruments or components of instruments that were not part (or not considered as a relevant part) of the existing H-S tree. To that end, the composite nature of two very different groups of objects-acoustic instruments equipped with timbre modifiers (case study 1$)^{2}$ and electronic devices used to produce sound in a musical context (case study 2$)^{3}$-are scrutinized. The first group is traditionally present in the H-S scheme, though without the inclusion of the timbre modifiers. The second group, however, did not appear in the original design of the system.

1. The MIMO (Musical Instruments Museums Online) project, gathering eleven museums from six different countries, was launched in 2009 and aims to provide images and information about the instruments kept in the participant institutions (about $40 \%$ of Europe's and $16 \%$ of the world's heritage of historic and non-European musical instruments in public possession), within the framework of the European Digital Library "Europeana." In addition, the MIMO group is also working on "multilingual content such as dictionaries for controlled vocabularies for musical instruments databases ensuring a consistency on different languages ..., comparing non-specialists vocabulary with synonyms, terms and classification systems used by professionals, enabling a more specific research" (http:/www.mimo-project.eu/).

2. This study was led by Weisser.

3. This study was led by Quanten. 
The nature of the instruments under consideration was the most important theoretical point of departure, followed by the choice not to entirely abandon the H-S taxonomy. As the H-S system was initially designed to classify acoustical instruments, the changes introduced by the current approach in case study 1 are less radical than those demanded by the specificities of electronic configurations. As a consequence, the results of case study 1 could more easily be implemented in the existing databases, whereas the results of case study 2 more drastically evoke a future of musical instrument classification in which tree structures cease to play an exclusive role. Both case studies, however, are meant to immediately improve H-S classification in which, today, multiplicity is all too easily neglected.

This proposal is based on ideas that were already present - although rarely used - in Hornbostel and Sachs's original 1914 text: composite instruments and temporary links. Such ideas were proposed in order to increase the flexibility of the system. It is worth noting that up till now, scientists and museum curators used the H-S system as a conceptual framework, to be refined, reviewed, augmented, and amended, but rarely in a way that would make it "flexible." All the modifications introduced during the last century were made in order to establish it as rigid and unchangeable.

Our proposal does not solve (and does not aim to solve) all the problems of the taxonomical classification of musical instruments. We tried to include one further aspect of the complexity (the composite nature) of the instruments under consideration within the H-S classificatory scheme. Many features remain thus discarded. As explained above, this limitation is due to the fact that the H-S classification system works by reducing the concept of musical instruments. Hornbostel and Sachs appear to have been aware of the manifold issues raised by such a choice, even with respect to their highest level of division. As noted by Kartomi (1990:171), Hornbostel-Sachs, as "heirs to a long tradition of downward classification, ... were forced to conclude that reality as they conceived it was too complex to allow single-character division to operate beyond the first step [classification according to the sounding material] in their classification."

\section{Case study 1: Instruments with timbre modifiers}

The issue of musical timbre raises many questions among researchers and scientific institutions nowadays. Along with pitch, loudness, and duration, timbre is one of the fundamental parameters that define a sound. Timbre is a slippery concept that involves multiple factors (Leipp 1989:149). Within the overall instrumental timbre issue, interesting issues are created by specific devices: timbre-modifying mechanisms or timbre modifiers. Such devices - named after the term "voice modifiers," used by Don Niles (1989), to designate instruments that modify voices in Papua New Guinea-exist in instruments from almost every cultural area and belong to every organological family (see figure 1). A timbre modifier can be described as a mechanism that: (1) produces an effect which is a constitutive part of the timbre of the sounds generated by the instrument; (2) is not dependent on a specific playing 


\section{Organological family of the main instrument}

1. Idiophones
Device

1. Mirliton (singing membrane) in the sound box

2. Objects rattling on the soundtable or around the keys

3. Bells attached to the instrument

2. Membranophones

1. Mirliton (singing membrane) in the sound box

2. Cymbals, bells, jingles

3. Additional unplayed membrane

4. String above or under the skin

3. Chordophones 1. Sympathetic strings

2. Metal jingle

3. Curved wide bridge

4. Objects in contact with strings

5. Objects creating contact between strings and bridge

6. Semi-mobile bridge

4. Aerophones 1. Mirliton (singing membrane)

\section{Example}

African xylophone (balafon)

African lamellophone (mbira)

Indian concussion sticks

(cimta)

Tshokwe hourglass drum (mukupiela) (Africa)

Tambourine, daire (Balkans, Persia and Central Asia)

Western drum bass

French tambourin de Provence, North African bendir

Norwegian hardingfele, Indian sarangi, European viola

d'amore

Guinean bridge harp (nkoni), Moroccan lute (guinbri)

Indian rudra vina, Kenyan lyre (obokana)

Bray pins, Ugandan harp (endongo)

Ethiopian lyre (bagana), Indian lute (tambura)

Trumpet marine, hurdy-gurdy

Chinese flute (dizi), Western eunuch flute, Korean taegum

Figure 1. Examples of timbre-modifying devices in instruments belonging to all four H-S categories.

technique; (3) is not needed for the production or the transmission of the vibration or the static equilibrium of the instrument. ${ }^{4}$

In several cultural areas, the use of timbre modifiers can be considered as a key feature. In African music, "particularly in instrumental music, a persistent search for a 'burred' or 'buzzing' tone is widespread, and various vibrating devices are frequently added to such instruments as the sanza, or likembe, and xylophone, among others" (Merriam 1962:120-30). In Indian classical music, the search for timbre enrichment can be qualified as a "constant in ... musical aesthetics" (Bertrand 1992:18). Timbre modifiers are of great importance, from both emic and etic points of view. Sounds produced with a modifier may carry a special meaning in a culture, such as the voice of the ancestors in Zimbabwean mbira music

4. These qualifications are used in order to limit the size of the corpus determined by the definition, since all the constitutive parts of an instrument have an influence on the resulting timbre. The technique-dependent factors of playing were also omitted for the same reason. 
(Berliner 1993). The mechanism giving a specific sound-and the specific tone colour - can embody symbolic value. In Indian chordophones, such as the sitar, the vina, and the tambura, this mechanism is called a javari (sometimes spelled jiwari or jawari), a word meaning "giving life" (Junius 1974:85, 105). The buzzing tone colour of the Ethiopian bagana (Weisser 2005) is considered as an essential condition for the identity of the instrument: if it does not produce buzzing sounds, the instrument is not a bagana.

The importance of timbre modifiers has also been acknowledged by researchers. Aubert (1991:108) considers them as "secondary principle of the instrument's sound production mechanism"; Tracey considered the presence or absence of a mirliton as a significant trait for the classification of lamellophones (1948, cited in Kubik 1999:28). According to Dehoux (1986:94-96), the buzzing elements of the sanza lamellophone from Central African Republic cannot be considered as accessories as they are a constitutive part of the instrument, "radically modifying the conventional sound qualities" and deeply "modifying the structuring of the sonorous space."

This case study investigates the possibility of introducing timbre modifiers into the H-S classification. Given the widespread and worldwide use of the H-S scheme, remaining as close as possible to its existing codes and categories was considered a requirement, even though their relevance might be discussed (especially in regard to the subcategorization of idiophones). Our proposal aims to make up for the fact that the sounds produced by instruments are not considered relevant criteria in the H-S system, even at the most detailed level. As we consider, with Emile Leipp (1989:160), that musical instruments are by definition "machines that produce sounds," such an omission is very problematic.

We thus differentiated timbre modifiers according to the type of mechanicalacoustical modification they induce in the "main" sound. Using such a criterion results in the two following categories: (1) timbre modifiers that add sonorous components to the main sounds (or "secondary instruments") and (2) timbre modifiers that modify the main vibration (or "vibration modifiers")

This categorization can be applied without detailed acoustical or organological analysis. Among chordophones and membranophones, the location of the device will provide sufficient clues for the classification. A device located far away from the vibrating element (string or membrane), probably belongs to the "secondary instruments" category: for example, a modifier inserted on the sound box would fall into this category.

In order to include the devices under the numerical codes of the Hornbostel-Sachs classification system, the plus (+) and slash (/) signs can be used. The plus sign indicates that sonorous components are added to the "main" instrument (category 1, "secondary instruments"). Such a sign was already employed by Hornbostel and Sachs (1961:12): "These innumerable cases in which an instrument is composed of parts which in themselves belong to different groups of the system could be indicated by linking appropriate figures by a plus sign." In this particular context, the + is followed by the full code of the secondary instrument. Secondary instruments are often idiophones; since the criterion for subcategorization in this family 


\begin{tabular}{|c|c|c|}
\hline Instrument & $\begin{array}{l}\text { Current } \mathrm{H}-\mathrm{S} \text { category and } \\
\text { numerical code }\end{array}$ & $\begin{array}{l}\text { Suggested H-S category } \\
\text { and numerical code }\end{array}$ \\
\hline $\begin{array}{l}\text { Tambourine (frame drum } \\
\text { with cymbals inserted in } \\
\text { the frame) }\end{array}$ & $\begin{array}{l}\text { Single-skin frame drum } \\
211.311\end{array}$ & $\begin{array}{l}\text { Single-skin frame drum } \\
\underline{\text { with cymbals }} \\
211.311+111.142\end{array}$ \\
\hline $\begin{array}{l}\text { Tshokwe mukupiela } \\
\text { hourglass drum (equipped } \\
\text { with a singing membrane } \\
\text { or mirliton in its sound } \\
\text { box) }\end{array}$ & $\begin{array}{l}\text { Individual double-skin hourglass } \rightarrow \\
\text { drum } \\
211.242\end{array}$ & $\begin{array}{l}\text { Individual double-skin } \\
\text { hourglass drum with } \\
\text { mirliton } \\
211.242+2.4\end{array}$ \\
\hline $\begin{array}{l}\text { Viola d'amore (with } \\
\text { sympathetic strings) }\end{array}$ & $\begin{array}{l}\text { Necked box lutes sounded by } \\
\text { bowing a bow }\end{array}$ & $\begin{array}{l}\text { Necked box lutes } \\
\text { sounded by bowing a } \\
\text { bow with sympathetic } \\
\text { strings } \\
321.322-71+3\end{array}$ \\
\hline
\end{tabular}

Figure 2. Proposal for the integration of secondary instruments into the H-S classification. Proposed changes are underlined.

is the way instruments are set vibrating (see, for example, 111 "struck directly" or 112 "indirectly struck," (Brown 1984:279)), the codes and subcategories of the corresponding independent instrument are to be used - even if the way the device is set vibrating is slightly different when it is a modifier than when it is a "standalone" instrument. If the secondary instrument is a string or a membrane, it is also possible to use the corresponding number used in H-S classification (3 for a string, 2.4 for a singing membrane or mirliton, 2 for an unplayed additional membrane; see figure 2).

Several other items of information can be included, including the number of secondary instruments and their location on the instrument. The number of such devices as sympathetic strings or rattles can be detailed by using an asterisk (*). For a viola d'amore with six sympathetic strings, the H-S code becomes $321.322 .71+3 * 6 .{ }^{5}$ Additional information about the precise location of the modifier can be added between parentheses: (1) the vibrating element, (2) the sound board, (3) the sound box/tube/shell (see figure 3).

For the second category of timbre modifiers (the "vibration modifiers"), the slash sign (/) can be used to indicate that the device transforms the main vibration. Such modifiers have been found to date on membranophones and chordophones only. This category of "vibration modifiers" can be divided into subcategories, according to the nature of the modifier. The criterion for the first level of subdivision would be whether the modification is generated by using a specific shape for an existing piece (/1), by adding a piece (/2), by removing a piece (/3), or by combination of the above (adding a specifically shaped piece, /4). Further details about the modifier's location can be provided between parentheses, as for the "secondary instruments" category. A modifier located above the vibrating element (skin or

5. Underlining marks proposed changes to the H-S classification. 


\begin{tabular}{|c|c|c|}
\hline Instrument & $\begin{array}{l}\text { Current H-S category } \\
\text { and numerical code }\end{array}$ & $\begin{array}{l}\text { Suggested H-S category and } \\
\text { numerical code }\end{array}$ \\
\hline $\begin{array}{l}\text { African xylophones (e.g., } \\
\text { balafon) with calabash } \\
\text { resonators equipped with } \\
\text { singing membrane) }\end{array}$ & 111.212 & $\begin{array}{l}\text { Set of percussion sticks, with } \\
\text { mirliton in the sound box } \\
111.212 \underline{+2.4(3)}\end{array}$ \\
\hline $\begin{array}{l}\text { Lamellophone with rattling } \\
\text { objects placed on the } \\
\text { soundtable }\end{array}$ & $\begin{array}{l}\text { Lamellophone with } \\
\text { resonator } \\
122.12\end{array}$ & $\begin{array}{l}\text { Lamellophone with resonator, } \\
\text { with rattles on the sound table } \\
122.12+112(2)\end{array}$ \\
\hline $\begin{array}{l}\text { Lamellophone with rings } \\
\text { around their lamellae (see } \\
\text { figure 5) }\end{array}$ & $\begin{array}{l}\text { Lamellophone with } \\
\text { resonator } \\
122.12\end{array}$ & $\begin{array}{l}\text { Lamellophone with resonator, } \\
\text { with objects rattling around the } \\
\text { lamellae } \\
122.12+112 \text { (1) }\end{array}$ \\
\hline
\end{tabular}

Figure 3. Proposal for the integration of secondary instruments into the H-S classification, with their location. Proposed changes are underlined. Italicized digits in the numerical code correspond to the italicized part of the modifier's description.

string) will be indicated by "(1.1)" and a modifier located under it will be coded "(1.2)." This makes it possible to include the modifier in the classification system with a greater degree of accuracy (see figure 4).

We opted for the action of the modifier as the main principle for subdivision, and not the perceived modification the modifier induces. This choice was made for practical reasons: a perceptual criterion would require in-depth acoustical and perceptual investigations on a very large number and wide range of musical instruments. Moreover, it appears that very diverse devices can generate very similar perceptual effects - see namely, the "buzzing" characteristic tone colour of the bagana (Weisser 2005), which is produced by a vibration modifier, in comparison to the buzzing tone colour of the sanza, which is produced by a secondary instrument (Fales and McAdams 1994). And the reverse might well be true, too.

\begin{tabular}{|c|c|c|c|}
\hline Instrument & $\begin{array}{l}\text { Current H-S category } \\
\text { and numerical code }\end{array}$ & & $\begin{array}{l}\text { Suggested H-S category and } \\
\text { numerical code }\end{array}$ \\
\hline $\begin{array}{l}\text { Bendir drum } \\
\text { (North-Africa) }\end{array}$ & $\begin{array}{l}\text { Single-skin cylindrical } \\
\text { drum } \\
211.311\end{array}$ & $\rightarrow$ & $\begin{array}{l}\text { Single-skin cylindrical drum with } \\
\text { added modifier under the skin } \\
211.311 \underline{2(1.2)}\end{array}$ \\
\hline Lyre bagana (Ethiopia) & $\begin{array}{l}\text { Box lyre } \\
321.22\end{array}$ & $\rightarrow$ & $\begin{array}{l}\text { Box lyre with added modifier } \\
\text { under the strings } \\
321.22 / 2(1.2)\end{array}$ \\
\hline
\end{tabular}

Figure 4. Proposal for the integration of vibration modifiers into the H-S classification, with their location. Proposed changes are underlined. Italicized digits in the code correspond to the italicized part of the modifier's description. 


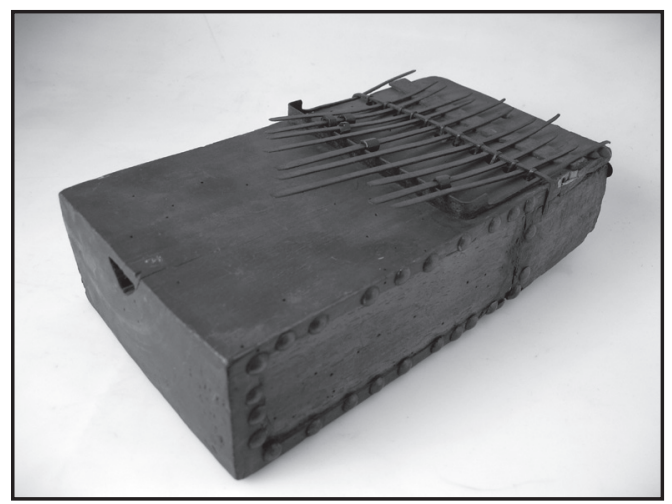

Figure 5. African sanza with rings rattling around the lamellas. Musical Instruments Museum, Brussels (Belgium), inv. 1767 (photo (C) mim).

\section{A closer look at organological families}

\section{Idiophones}

Among idiophones, all the modifiers found so far belong to the first category (devices that add sonorous components to the main sounds, or secondary instruments). Modifiers are either mirliton $(\underline{+2.4})$ or secondary idiophones: bells $(+111.242)$, rattles $(+112.1$, see figure 5), etc.

As suggested above, additional details (such as the precise location of the secondary instrument) can be indicated. If several secondary instruments of the same kind are present on the instrument, it is possible to mention their exact number by using the asterisk. Where different kinds of modifiers are present, it is also possible to detail them by using a succession of the corresponding codes, each preceded by $\mathrm{a}+$.

\section{Membranophones}

Among membranophones, the question of the unplayed second skin of drums such as the bass drum is often problematic. In institutions such as museums, information about the idiomatic use of instruments is frequently incomplete. Curators are well aware of the difficulty in determining whether a membrane is played or not. However, the presence of a second membrane is very important in regard to the sound produced. Acousticians consider two membranes coupled by an enclosed air cavity as one of three major categories of drum (together with a single membrane stretched over an open shell, such as the tom-tom and the conga, and a single membrane coupled with an enclosed air cavity, such as the timpani; cf. Rossing et al. 1992:84).

In a recent proposal, Jeremy Montagu (2008) acknowledged that a second skin should "count" because it does affect the sound, whether it is struck or not. He therefore suggests deleting the term "usable" from the 211.212 definition, transforming the latter into a simple "double-skin cylindrical drums." The present pro- 


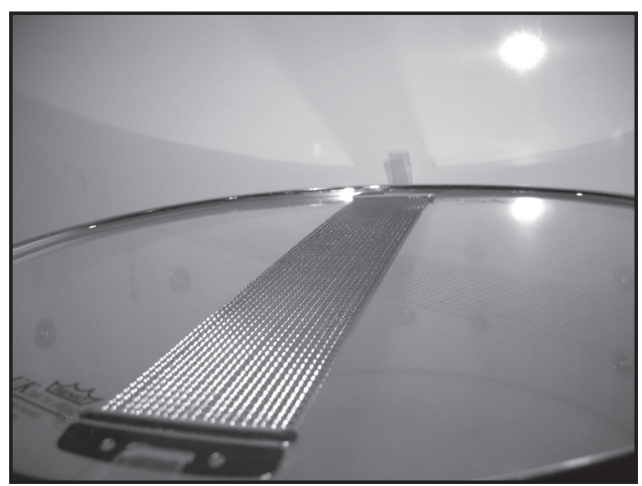

Figure 6. Snare drum, Educational Service. Musical Instruments Museum, Brussels (Belgium) (photo $\subset$ mim).

posal suggests keeping the existing "single-skin" subcategories and adding +2 for the additional unplayed membrane. The "double-skin" subcategories would only be relevant for instruments with both membranes played or whose number of played membranes is unknown. When both skins are known to be used, the 211.212.12 code can still be used (for double-skin cylindrical drums, both membranes played). When the number of played skins is undetermined, the code should be 211.212.11 (currently used for double-skin cylindrical drums, one skin played). It would thus become: "double-skin cylindrical drums, number of played membranes undetermined." Although less elegant than the simple differentiation between "singleskin" and "double-skin" (the latter either with one skin or both skins played), this solution would have the merit of transparency regarding the available information about the instrument and of making possible a differentiation according to the nature of the second skin's action on the sound. If played, it is part of the instrument and should be included in the main subcategorization and code; if not, it is a timbre modifier, over which the musician has little or no control (and should therefore be indicated by $\mathrm{a}+$ ).

The question of the snare drum also raises several issues. Non-Western snare drums (such as the North African frame drum, the bendir, see figure 1) are usually equipped with a string stretched across the membrane, either under or above it. It can be considered as a vibration modifier, not producing sound by itself. The Western snare drum, on the other hand, is a "two-headed instrument ... [with] strands of wire or gut stretched across the lower (snare) head. When the upper (batter) head is struck, the snare head vibrates against strands of wire or gut (the snares)" (Fletcher and Rossing 1998:602). The snare, especially if it is of wire (figure 6), probably acts in two ways: it modifies the vibration of the unplayed skin, but it also produces sounds by itself, as it acts as a rattle. Players are familiar with a resonance phenomenon involving snare drums: a metallic sound deriving from the snare is slightly audible due to resonance with other instruments' sounds, although the drum itself is not directly played. Montagu (1970:111) has also noted that the snare of the medieval tabor has pitch of its own. 


\begin{tabular}{lll} 
Instrument & $\begin{array}{l}\text { Current H-S category } \\
\text { and numerical code }\end{array}$ & $\begin{array}{l}\text { Suggested H-S category and numerical } \\
\text { code }\end{array}$ \\
\hline Snare drum & $\begin{array}{l}\text { Double-skin cylindrical } \\
\text { drum }\end{array}$ & $\rightarrow \frac{\text { Single-skin cylindrical drum with unplayed }}{\text { skin with added modifier above the skin, }}$ \\
& 211.212 & $\underline{\text { acting as a rattle }}$ \\
$211.21 \underline{1+2[/ 2(1.1)}=112]$
\end{tabular}

Figure 7. Proposal for the integration of timbre modifiers into the H-S classification. Example of the snare drum. Proposed changes are underlined. Italicized and bold digits in the code correspond to the italicized and bold parts of the modifier's description.

Both actions should be indicated in the H-S system, using an equals sign (=) to indicate that the added modifier acts also as a rattle. The use of square brackets might contribute to making this clearer (figure 7).

The details of the numerical code of the modifier are as follows:
$+2 \quad$ with an unplayed membrane
$+2[/ 2 \quad$ with an unplayed membrane equipped with an added vibration
modifier
$+2[/ 2(1.1)] \quad$ with an unplayed membrane equipped with an added vibration
$+2[/ 2(1.1)=112] \quad \begin{aligned} & \text { modifier located above the skin } \\ & \text { with an unplayed skin equipped with added modifier above the skin, }\end{aligned}$ acting as a rattle

Non-sounding material applied directly to the skin is frequently found around the world: the Indian tabla, and African and Papua New Guinean drums (equipped with beeswax blobs) are just a couple of examples of such devices, which have an influence on the spectrum of sounds produced. In the case of the Indian tabla, a noticeable harmonization is observed (Fletcher and Rossing 1998:611-15). Integration of such vibration modifiers in the H-S classification is illustrated in figure 8.

Vibration modifiers of this kind play an important part in pitch determination. By harmonizing timbre, pitch sensation is strengthened. As noted by Don Niles (pers. comm., 2010), Papua New Guinean drums are tuned by adding beeswax blobs, even though it is the spectral pitch that is most probably adjusted.

\begin{tabular}{lll} 
Instrument & $\begin{array}{l}\text { Current H-S category and } \\
\text { numerical code }\end{array}$ & $\begin{array}{l}\text { Suggested H-S category and } \\
\text { numerical code }\end{array}$ \\
\hline Tabla & Kettledrum drum & $\rightarrow \begin{array}{l}\text { Kettledrum drum with added vibration } \\
\text { modifier above the skin }\end{array}$ \\
211.1 & $211 / 2(1.1)$
\end{tabular}

Figure 8. Proposal for the integration of timbre modifiers into the H-S classification. Example of the tabla. Proposed changes are underlined. Italicized digits in the code correspond to the italicized part of the modifier's description. 


\section{Chordophones}

Chordophones comprise a wide range of timbre modifiers belonging to both the "secondary instruments" and "vibration modifier" categories. Some instruments, such as the Indian sitar, are equipped with both kinds of modifier: sympathetic strings and curved wide jiwari bridges (for both main strings and sympathetic strings; figure 9).

The details of the numerical code of the modifier are as follows:

$\begin{array}{ll}/ 1 & \text { with a vibration modifier being a specifically shaped piece } \\ / 1(1.2) & \text { with a specifically shaped modifier under the strings (bridge) } \\ / 1(1.2)+3 & \text { with a specifically shaped bridge and sympathetic strings } \\ / 1(1.2)+3 / 4 & \begin{array}{l}\text { with a specifically shaped bridge and sympathetic strings, those } \\ \text { strings being equipped with an added specifically shaped piece }\end{array} \\ / 1(1.2)+3 / 4(1.2) & \begin{array}{l}\text { with a specifically shaped bridge and sympathetic strings, those } \\ \text { strings being equipped with an added specifically shaped modifier } \\ \text { under the strings (bridge) }\end{array}\end{array}$

Such a high level of precision can be relevant: it seems that some sarangi (Indian bowed chordophone with sympathetic strings) can (but not always do) have such a slightly curved jiwari bridge for their sympathetic strings, depending on musical and aesthetical choices and gharanas (schools). The number of sympathetic strings (which can be detailed using * after the +3 part of the code) also appears to depend on stylistic schools. Being able to differentiate between instruments can then be considered as pertinent in a classification system.

In the "secondary instruments" category, a "vibrating bridge" rattling against the soundtable (figure 10) can be found in the hurdy-gurdy and the trumpet marine. Especially in the case of the latter, such a bridge is responsible for the "trumpetlike" timbre of the instrument.

Vibrating bridges can be indicated by adding $+112(1.2)$ (rattle located under the vibrating elements, i.e., the strings) to the respective numerical codes and subcategories of the hurdy-gurdy and the trumpet marine.

\begin{tabular}{|c|c|c|c|}
\hline Instrument & $\begin{array}{l}\text { Current H-S category anc } \\
\text { numerical code }\end{array}$ & & $\begin{array}{l}\text { Suggested H-S category and numerical } \\
\text { code }\end{array}$ \\
\hline Sitar (India) & Necked bowl lute & $\rightarrow$ & $\begin{array}{l}\text { Necked bowl lute, with specifically shaped } \\
\text { modifier under the strings (bridge) and } \\
\text { sympathetic strings (themselves with a } \\
\text { specifically shaped, added modifier under } \\
\text { the strings (bridge) }\end{array}$ \\
\hline & 321.321 & & $321.321 / 1(1.2)+3 / 4(1.2)$ \\
\hline
\end{tabular}

Figure 9. Proposal for the integration of timbre modifiers into the H-S classification. Example of the sitar. Proposed changes are underlined. Italicized and bold digits in the code correspond to the italicized and bold parts of the modifier's description. 


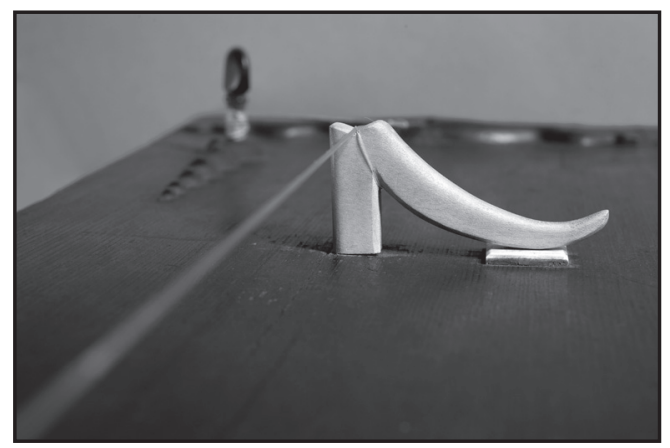

Figure 10. Trumpet marine (detail). Musical Instruments Museum, Brussels (Belgium), inv. 0217 (photo $\mathbb{C}$ mim).

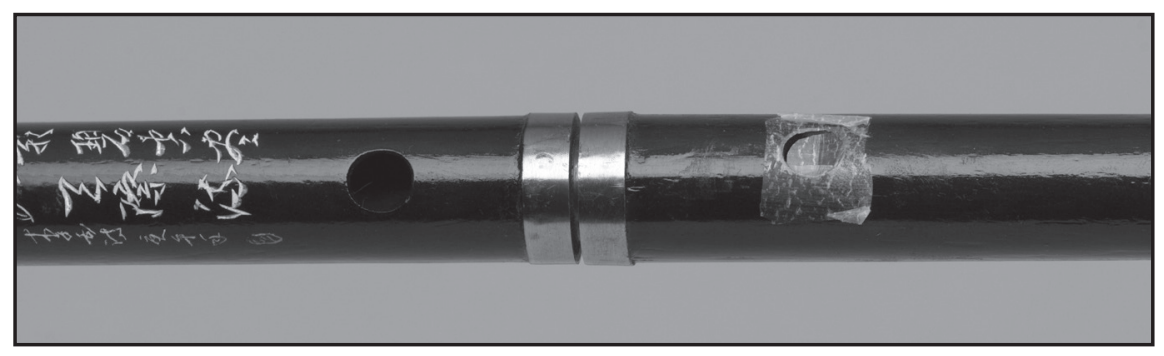

Figure 11. Chinese membrane transverse flute-dizi. Musical Instruments Museum, Brussels (Belgium), inv. 1991.072 (photo (C mim).

\section{Aerophones}

Among aerophones, the modifiers are generally secondary instruments, such as singing membranes (figure 11) or rattles. They can be indicated by adding, respectively, +2.4 and +112.1 to their current $\mathrm{H}-\mathrm{S}$ numerical codes and subcategories.

Aerophones seem to be rarely (perhaps, never) equipped with vibration modifiers. Since the main vibration is created by vibrating air (for flutes), reed(s) (for reed instruments), or lips (for lip-reed instruments), this absence is not surprising.

In the aerophones family, instruments are often "multiple": the paired reed pipes found in the Mediterranean region, the Balkan double flutes, and, of course, the organs (European or Asian) are but some examples of the possibilities of coupling individual aerophones. In the context of the present paper, only drone (reed or edgetone) pipes can be considered as secondary instruments. Indeed, only those fulfil the second condition formulated in the definition of timbre modifiers presented above: the timbre modification is not dependent on a specific playing technique. ${ }^{6}$ In these cases, the H-S code of the drone can be added after a + sign following the "main" instrument's code.

6. This fact also excludes aerophones played with a hummed drone from the category of instruments with timbre modifiers. 


\section{Conclusion}

In this case study, we investigated the possibility of introducing timbre modifiers into the H-S classification. It can (and was) argued that every part of a musical instrument plays an important role in the timbre of the produced sounds. Why strive then for the inclusion of these devices into the system? First of all, because timbre modifiers are "something more": Leipp (1989:160) stated that every musical instrument, in its most simple and reduced mechanical form, is composed of an excited element and an amplifying element. Timbre modifiers can be considered as elements designed explicitly to add to or modify this configuration. It is important then to include them in a classificatory scheme based on the concept that the "physical characteristics of sound production"7 (Hornbostel and Sachs 1961:8) are of a primary importance for an object to be called a musical instrument.

Second of all, we consider that the introduction of timbre modifiers into the $\mathrm{H}-\mathrm{S}$ system is the first step towards a new, modular way to encompass acoustical musical instruments: if we consider a musical instrument as a complex, sound-producing device, each constitutive part should be seen as an important component, worth being taking into account in a classificatory act. This new approach would definitely require a non-taxonomic conceptual framework (see discussion section below).

It's worth noting that in the last decade, the fields of musical data mining, indexing, and musical information retrieval (MIR) have thrown up a new need for the classification of musical instruments. The identification and the classification of instruments (as well as, instrumental timbre in general) are extremely important features in the automatic identification of musical genres (see, e.g., McKay and Fujinaga 2005). A significant amount of work has already been done on the subject, and joint investigations would benefit both (ethno)musicologists and organologists, as well as computer and information scientists working on the "weird and complex machines" that musical instruments are.

\section{Case study 2: On the modular nature of electronic instruments and their hierarchic classification}

In the twentieth century, the world of electronic sound was explored by engineers as well as by composers and other musicians. As early as 1897, Thaddeus Cahill developed his telharmonium, a gigantic tonewheel organ, technically resembling the later Hammond instruments. The device generated electrical audio signals using

7. Actually, the first subdivision creating the four traditional categories was not carried out according to the "physical characteristics of sound production." Hornbostel and Sachs instead looked at the "initial vibration" produced in a musical instrument, which is only a pars pro toto referred to in their introduction to the classification. In the case of a piano, for instance, it is the vibration of the soundboard which to a major extent sets the air particles vibrating, and not the string attached to it. Nevertheless, the piano is considered as a chordophone and not as an idiophone, as a string produces the "initial vibration," which is transmitted to the soundboard and, in turn through air particles, to our ear. 
the principle of additive synthesis. The telharmonium was actually played more or less as if it were a traditional acoustic organ, being equipped with a keyboard, stops, and even foot pedals. The way in which the sounds were generated, however, differed significantly from the way a traditional acoustic organ generates them. The same can be said for other early electronic instruments, such as the theremin, ondes martenot, and trautonium. All of these machines, however, were mostly used to replace traditional instruments. This situation changed considerably in the late 1940s and the 1950s in favour of electronic devices reflecting completely new aesthetics. In post-war Paris, Pierre Schaeffer and Pierre Henry developed musique concrete, and some years later fully electronic tape compositions were produced at the NWDR/WDR (Nordwestdeutscher Rundfunk/Westdeutscher Rundfunk) studio in Cologne. Protagonists of early multiple serialism, such as Karel Goeyvaerts and Karlheinz Stockhausen, wanted to be able to reflect the structure of an entire composition in a single sound structure. This meant that they had to "compose" sounds. Behaving in a way as architects or chemists of music, these composers used electrical audio signals, sound particles, to build complexes, constructions of sound. Those sounds were no longer bound to physical laws of instrumental and space acoustics, nor to the physical and mental limitations of human musicians. No instrument was played during a performance, and the music sounding from speakers could not possibly be realized "live" by musicians on stage. As a result, the relation between composer, score, musicians, and public changed thoroughly; electronic tape music might actually be called a temporal sculpture, a montage of sound.

From 1954 to 1964, the composer and music theorist Gottfried Michael Koenig worked as a studio technician at the Cologne electronic music studio, being responsible for the technical realization of a considerable part of the electronic tape music composed during the pioneering years of the Cologne studio, including Stockhausen's famous spatial composition Gesang der Jünglinge (1956), György Ligeti's Artikulation (1958), and Koenig's own Essay (1957-58). In those days, Koenig was known to be one of the top specialists in electronic sound design. In the 1960s, he even had a considerable influence on the development of studio equipment and early, revolutionary ways of "digitizing" the process of sound production. In many of his theoretical writings, Koenig refers to the specificity of making sound within the context of an early studio, sound that, in his opinion, had to be "typically electronic" - that is, crossing the limits of instrumental acoustics - and of the way in which sound had been conceived up to that moment:

there is a fundamental difference in the procedure of production, in the handling of the "machines" whose features go beyond those of the original musical instruments. From this state of affairs, consequences had to be drawn and sound had to be defined in terms that instrumental sound cannot have, due to the method of its production ... All means by which the technique of montage exceed the spontaneity of music-making contradict the usual reactions of musicians, point the composer to the idiomatic production procedures of electronic music, and force him to the consequences that follow. (Koenig 1992:92-93, transl. Quanten) 


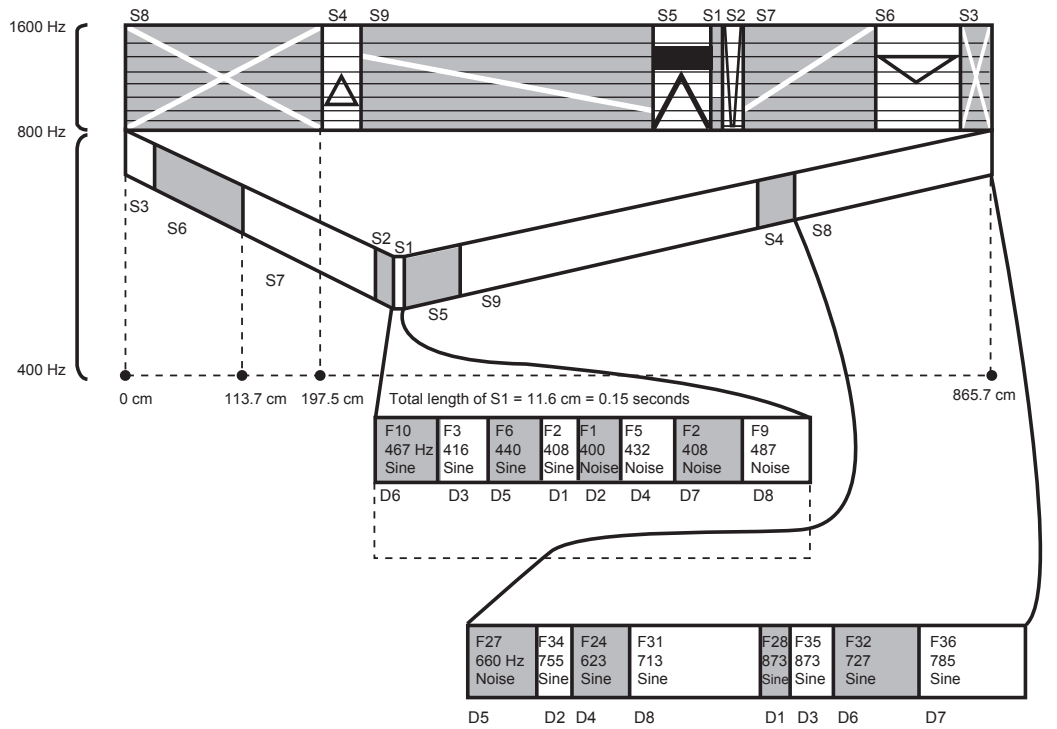

Figure 12. Sound complex designed by the composer Gottfried Michael Koenig for his tape composition, Essay (drawing from Quanten 2009:233).

In the 1950s, studio equipment was quite primitive. A sound could not just be "programmed" and played, but required several acts of processing. For instance, a composer could use a (white) noise generator to create his or her initial "rough" sound material — a random voltage fluctuation — almost as if he were a sculptor selecting a piece of wood or rock. In a next step, he could start "sculpting" by using a filter. This device enabled him to tailor the random amplitude curve into a narrower bandwidth in which a globally defined field of frequencies could be distinguished. A next step could be the montage, a process in which he used only a few inches of the sound material, connecting it to other pieces; such a montage of tiny pieces of tape becomes a sound complex, which can differ distinctly from a sound produced by an acoustic or contemporary electronic instrument. In yet another step, this complex of separately designed sounds could be transformed again: for example, by filtering it, by modulating pitches, temporally stretching or ring-modulating it, etc. Koenig once wrote he had been working for weeks on end just to realize a few seconds of the "swarms of sounds" Stockhausen wanted to use in his Gesang der Jünglinge. Actually, an entire piece could have consisted of "one single sound," a continuous sound ("kontinuierliche Klang"), slowly changing in all its parameters.

The drawing presented in figure 12 graphically represents a sound complex Koenig designed for his own tape composition, Essay (Quanten 2009:233). It contains dozens of sine tones and filtered noises, all generated and/or filtered separately and subsequently glued together. The smallest sound particles have a duration of approximately just 1/80 of a second and cannot be heard as separate acoustic events. This sound complex takes the form of a triangular-shaped move- 
ment in frequency space, of which only the general sound silhouette is perceivable. These kinds of sound can be described as typically "electronic." However, this sound is still only rough material that is not used as such in the composition. Before Koenig actually uses it in the piece, the agglomerate is transformed several times, using ring modulators, filters, etc.

In such a case, an enormous gap appears between the traditional "excitation of a sounding material," which the H-S classification is based upon, and the newly discovered practice of electronic sound design.

What "musical instrument" produced the actual sounds heard by the audience in the concert hall? Actually, none of the machines mentioned above really produces sound; the loudspeaker does. All devices, however, are "instruments" used in a (time-consuming) process of preparing or sculpting the sounds. They are part of a production process in which the studio technician creates the exact temporal succession of electric amplitude values, prescribed by the score. Does the technician play instruments? Maybe so. Is a filter an instrument? As it does not independently produce sound, it is not - at least according to the basic rules of the H-S system. So should we exclude filters from the classification tree? And what if they are played, as is the case in several avant-garde pieces written in the $1960 \mathrm{~s}$, in which sounds produced by musicians are filtered in real-time by a "sound engineer"?

\section{An electronic instrument might not be "one" but "many"}

In 1990, a group of scientists developed a fifth category of the H-S system (Bakan et al. 1990), containing both analogue electronic and digital musical instruments. ${ }^{8}$ This research group, when developing their Games Classification System (GCS), decided not to include the studio modules described above, as this would have contradicted the basics of the H-S taxonomy. They clearly considered the presence of an oscillator circuit (audio signal generator) in a device to be of crucial importance in calling it an "electronophone." Hence, they included synthesizers (electronic oscillators) and tonewheel instruments (electromechanical oscillators), but omitted electro-acoustic instruments (e.g., electric guitars, considered a chordophone in GCS) from the fifth category. This high-level differentiation between electroacoustic and tonewheel instruments, however, is a bit strange, considering the aim of scientifically linking objects, which seemed to have been a goal of Hornbostel and Sachs (1961:5). In both cases, a loudspeaker (transducer module) produces the sound heard by the listener; in both cases, an amplifier module amplifies the electrical sound signal; in both cases, pick-ups (transducer modules) are used to transform a movement of metal into an electrical sound signal. Indeed, there is no acoustic vibration in, for example, a Hammond organ. This, however, does not mean that the huge physical resemblance between the active components of both

8. The older classifications of electronic instruments in the H-S framework, developed by Sachs (1940) and Galpin (1937) are not taken into consideration in this paper as they predate the development of very important technologies and devices. 
sound machines should simply be ignored by creating a differentiation at the highest level of subdivision.

Most people consider a synthesizer to be a musical instrument. Nevertheless, it consists of the same modules already found in the electronic studio. Actually, Stockhausen and Koenig used the same devices that constitute the famous Minimoog synthesizer. The difference is that, in this more modern, "transportable studio," they are linked together in a box equipped with a traditional keyboard, though this does not change the basic principles of electrical sound signal processing. In a Minimoog, there is still an oscillator module, generating, for instance, an electrical noise signal whose output is linked to a filter, etc. It is only that the idea of sound montage is not included in an analogue electronic synthesizer assemblage, making the way in which the instrument is played - that is, "live on stage"-resemble that in which "classical" instruments are. Just as the sound created in the electronic studio can be defined by referring to the several stages of its production process, the sound possibilities of the synthesizer are closely linked to the types of modules that build it up. Some synthesizers, for instance, contain only one oscillator, a filter, an amplifier, and a loudspeaker, whereas other types have several types of oscillators, filters, ring modulators, voltage control generators, etc. As a matter of fact, all of these devices could also be part of an electro-acoustic or tonewheel instrument. An electrical sound signal-whether produced by a string pick-up, a tonewheel-pick-up, or an electronic oscillator-can be transformed in real time by dozens of devices. This is, for example, the case with the experimental instruments built by the American composer Mark Applebaum. Even in the famous RCA Mark I Synthesizer, electrically excited tuning forks, instead of oscillator circuits, are used to produce the initial sound signals. In this case, an "electro-acoustic idiophone" contains exactly the same components as some synthesizers, offering its user a wide range of sound transformation possibilities. When forcing such a machine into the idiophone box, a lot of meaningful links are lost. The least we can state in this case is that the H-S system loses its scientific validity for highlighting resemblances between instruments.

In 2010, the MIMO team requested Quanten to develop a new subdivision of the H-S category of electrophones. This research led him to the conclusion that the modular nature of these instruments clearly contradicts the disposition of the classification system, which is fundamentally hierarchic, root-based. Significant differences and similarities between electronic and hybrid configurations cannot be shown in a tree taxonomy. An electronic or electric instrument is an assemblage; its instrumental features depend upon the specificity of the parts, the way in which they are linked, and the way the user can command them. Links between instruments can occur between all of these parts, micro- and macro-assemblages. An electric piano (A), equipped with filters, sine generators, ring modulators, etc., might have much more in common with a synthesizer (B) than another (very simple) synthesizer (C) has. This multitude of possibilities in electronic sound processing, however, is not "codable" in the fixed paths of the tree. If the multitude cannot be shown, the developer of the classification system necessarily has to choose subjective criteria of subdivision. The developers of the GCS, for instance, considered 


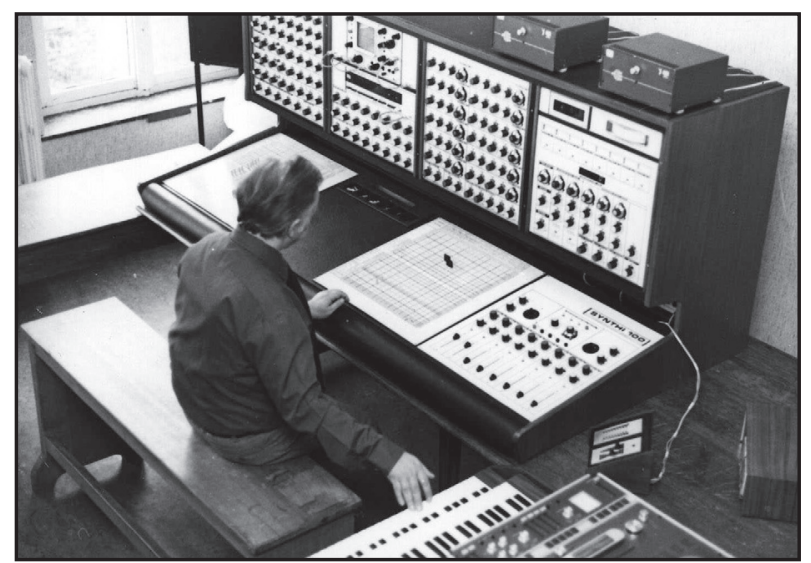

Figure 13. Lucien Goethals working with the IPEM's EMS Synthi 100 Synthesizer (photo C IPEM).

the features of "polyphony" and "memory" to be crucial enough to differentiate between synthesizers (Bakan et al. 1990:58-59).

From a certain point of view, this is a valid option. It is very important for a live synthesizer player to know whether he can simultaneously play more than one note and whether he can store settings or not. If, however, we switch from the stage to a studio (or to stage acts in a more experimental or avant-garde atmosphere), other features might become much more important. For instance, a musician or composer might be very interested to know whether the device is of the "preset" or "modular" type, or something in between. These are the characteristics Quanten chose to base his subdivision upon, without denying the subjective nature of this decision. His particular interest in (early) "studio-composed music" is also shown at the highest level of subdivision, where he differentiated between "modules" and "configurations." The GCS developers, on the other hand, considered it undesirable to include in the tree of musical instruments devices that themselves do not produce sounds, for this would have broken one of the most crucial basic rules of the H-S system.

By including a category of modules - along with the acceptance of musical instruments standing outside a nineteenth-century logic - it might become possible to reduce the subjective character of fixed strata or boxes assemblages are forced into. Using mathematical symbols such as,$+ *$, and $=$, one can include the parts of a configuration, making the code more complicated, but also more accurate (see the appendix for a presentation of the proposed subdivision of the electrophones category).

It is easy to use the system to differentiate between synthesizer configurations without having to leave the H-S taxonomy, as not only would the "box" be part of the code, but also the "contents." We will try to clarify this approach by applying it to three well-known, but quite different devices: the gigantic EMS Synthi 100 (with pin matrix interface, see figure 13), the flexible Korg MS-20 ("semi-modular" with patch override system), and the small Moog Satellite (preset). 
The EMS Synthi 100 is a configuration, in particular a synthesizer (523.1). It is an assemblage of several modules, including twelve $(* 12)$ oscillators (511.1), two $(* 2)$ noise generators $(511.2)$, four $(* 4)$ high-pass filters $(512.11)$, four $(* 4)$ lowpass filters (512.12), one band-pass filter (512.13), sixteen $(* 16)$ amplifiers (512.2), two $(* 2)$ reverberation modifiers $(512.3)$, three $(* 3)$ ring modulators $(513.2)$, three (*3) envelope generators (514.12), one sequencer (514.13), one random-voltage generator $(514.15)$, two $(* 2)$ envelope followers $(514.16)$, two $(* 2)$ slew limiters (514.18), two (*2) keyboards (514.21), and one pitch-to-control voltage converter (516.1). Hence:

\section{EMS Synthi 100}

$$
\begin{gathered}
523.1=511.1 * 12+511.2 * 2+512.11 * 4+512.12 * 4+512.13+512.2 * 16+512.3 * 2+ \\
513.2 * 3+514.12 * 3+514.13+514.15+514.16 * 2+514.18 * 2+514.21 * 2+516.1
\end{gathered}
$$

The codes and subdivisions used can be found in the appendix. The other two devices can be categorized as:

\section{Moog Satellite}

$$
523.1=511.1 * 1+512.12 * 1+512.13 * 1+514.11 * 1+514.12 * 2+514.21 * 1
$$

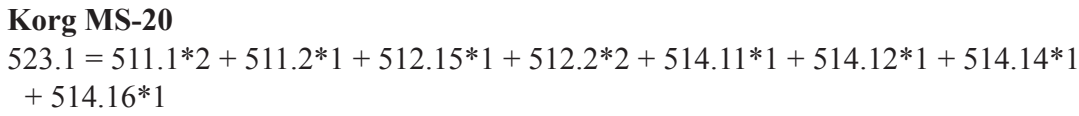

The more information added, the more accurate the description will be. Even just mentioning the number of oscillators, noise generators, and filters of the Synthi 100 will drastically reduce the number of matching devices. It shows what signal processing abilities the device encompasses and how flexible it is. It is quite simple to construct a software version of this system, enabling its user, for instance, to look for all synthesizers equipped with ring modulators or sequencers. Moreover, as already mentioned, this approach can also show similarities between "different" configurations such as synthesizers and sequencers (or experimental designs, not fitting one or another category). Let us, for example, take an early, unique, analogue sequencer, ${ }^{9}$ built at the IPEM (Institute for Psychoacoustics and Electronic Music) in Ghent, Belgium, in the second half of the 1960s:

IPEM Sequencer (Model 2, see Landrieu and Goethals 1973)

$523.2=511.1 * 1+512.2 * 1+514.13+514.21 * 1$

As shown in figure 14, all modules of this device also occur in the configuration of the Synthi 100, which actually contains a sequencer. A sequencer, thus, is a configuration within a configuration. So what's in a name? And what's in a code?

The exclusive use of a single H-S code cannot possibly show the convergences and divergences between these four devices. And as "linking" was one of the aims of Hornbostel and Sachs, it would be quite unscientific to ignore the contradiction between the nature of the instruments and the nature of the classification system.

9. This device is currently part of the collection of the Brussels Musical Instruments Museum (mim), inv. D1999.002-03. 


\begin{tabular}{cccc}
$\begin{array}{c}\text { EMS Synthi } 100=\mathbf{5 2 3 . 1} \\
\text { contains modules: }\end{array}$ & $\begin{array}{c}\text { Korg MS-20 }=\mathbf{5 3 2 . 1} \\
\text { contains modules: }\end{array}$ & $\begin{array}{c}\text { Moog Satellite }=\mathbf{5 2 3 . 1} \\
\text { contains modules: }\end{array}$ & $\begin{array}{c}\text { IPEM Sequencer }=\mathbf{5 2 3 . 2} \\
\text { contains modules: }\end{array}$ \\
\hline $511.1 * 12$ & $511.1 * 2$ & $511.1 * 1$ & $511.1 * 1$ \\
$511.2 * 2$ & $511.2 * 1$ & & \\
$512.11 * 4$ & & $512.12 * 1$ & \\
$512.12 * 4$ & & $512.13 * 1$ & \\
$512.13 * 1$ & $512.15 * 1$ & & \\
$512.2 * 16$ & $512.2 * 2$ & & \\
$512.3 * 2$ & & & \\
$513.2 * 3$ & $514.11 * 1$ & $514.11 * 1$ & \\
$514.12 * 3$ & $514.12 * 1$ & $514.12 * 2$ & \\
$514.13 * 1$ & $514.14 * 1$ & & \\
& & & \\
$514.15 * 1$ & $514.16 * 1$ & & \\
$514.16 * 2$ & & & \\
$514.18 * 2$ & & $514.13 * 1$ & \\
$514.21 * 2$ & & & \\
$516.1 * 1$ & & &
\end{tabular}

Figure 14. Table presenting the modules contained in the EMS Synthi 100 (synthesizer with pin matrix interface), the flexible Korg MS-20 (semi-modular synthesizer with patch override system), the small Moog Satellite (preset synthesizer), and the experimental

IPEM sequencer Model 2 configurations.

Moreover, in the age of computers, there is no need to stick to a nineteenth-century linear system to codify complex modern technology.

\section{Discussion}

The notion of a classification system implies the existence of a methodology, one that very often reflects the classifier's view of the "chaotic" cluster of objects that are submitted to intelligent ordering. A classification system reflects its inventor's ideas about the objects of his or her research as much as - if not more than - the way the inventor organizes those objects. Kartomi stated (1990:4) that the choice of distinguishing characteristics to construct a classification depends mainly on the cultural assumptions and purpose of the classifier. In nineteenth- and early-twentieth-century scientific culture, hierarchic tree structures were favoured for systematic ordering: animals, vegetation, and books were all to be subdivided into groups, subgroups, and sub-subgroups. Macrotaxonomy ordered the world - and, quite logically, the world of musical instruments according to Hornbostel and Sachs.

In 2011, however, we should ask to what purpose organologists still use the H-S classification system, knowing that its accuracy and flexibility as a tool to classify musical instruments has often been considered limited. On the one hand, organologists look upon the H-S system as just a way to easily create categories, of which the fundamentally subjective nature is considered with fatalism; on the other, many researchers continually strive for more accuracy, even when confronted with the sheer impossibility of classifying "difficult" instruments. Should we conclude that there is a fairly large discrepancy between the way we conceive of the H-S system in theory (a way to create groups and subgroups following some kind of subjective, 
but rather logical, path) and the way we handle it in practice (trying to incorporate the smallest details of some instruments by continuously creating new subcategories and suffixes to inch closer to the truth)? If H-S is but a way to organize our storage areas, then there is no point to relentless fine tuning. But a classificatory scheme is more than that. Grame already noticed in 1963 that "one can discern an alarming tendency on the part of some to use the system as a basis for scholarly investigation, when it is, in fact, merely an extraordinarily ingenious way of arranging musical instruments in one of many possible logical orders" (Grame 1963:138).

We can observe that the H-S system can be seen as objective, due to its analyticlike appearance and the scrutiny to which many organologists seem to subject it to; the more so as it is used by most museums, which provides the system with the status of being generally accepted by scientific "authorities." Its scientific appearance might seem to lay claim for its authority as the fixed, unchangeable truth, which might also lead to an easy-to-follow, authoritarian direction for young musicologists, curators and even tour guides in a museum.

Is the entire H-S endeavour bound to fail as a logical and universal classification system? In other areas of research, similar difficulties have been experienced in dealing with downward taxonomies, leading to the approach being eventually discarded in many disciplines. Does this mean that we should completely rethink the very concept of (taxonomical) classification of musical instruments? Why should the act of classification be based on one and only one facet at a time, as in the H$\mathrm{S}$ classificatory scheme? Is it even possible to justify, or even to reach a general agreement on which facet should be considered as the relevant one at a given step in the subdivision process?

During the past decades, computer and communication scientists have been influenced by the work of Gilles Deleuze and Félix Guattari (2009), who reacted strongly against "arboreal thought" and developed the idea of the "rhizome" (pp. 3-28). As shown above, the tree structure immediately excludes certain lines of thought. Using a "rhizome-inspired" approach, one might be able to overcome these problems. Complex objects could be accurately accounted for without the classifier having to choose only one route of description, a tracing. Links between instruments could be created at several levels. Using tags, we could create a "map"10 of musical instruments. This map might contain technical data (such as, shape, acoustical characteristics, playing techniques, etc.), as well as other information (such as, historical, sociological, geographical records, etc.), without there being a need to select only one. Using several types of connection, showing the complexity of sound and music production, we would be able to link flutes to organs and organs to synthesizers, sequencers to automated carillons and noise generators to snare drums. We would be able to classify contemporary sound sculptures without forcing them into boxes, ignoring their multifarious reality. ${ }^{11}$

10. "What distinguishes the map from the tracing is that it is entirely oriented toward an experimentation in contact with the real" (Deleuze and Guattari 2009:13).

11. "The map is open and connectable in all of its dimensions; it is detachable, reversible, susceptible to constant modification" (Deleuze and Guattari 2009:13). 
Such a framework would strive for a more holistic approach. Without a hierarchy, all the facets of an instrument can be considered as possibly relevant, including - why not? - its original H-S code and culture-emerging classification (Kartomi 1990:13-14). Nonetheless, it requires an important change in the way in which we, musicologists and organologists, conceive classification. We first need to realize and accept that the classificatory act is not necessarily a univocal act of "identification," as the H-S system is often used to accomplish. As noted by Montagu and Burton (1971:51), the H-S system is considered as a key ("a series of questions by the means of which an instrument can be identified"). When we use the H-S scheme for the classification of a piano, for instance, we often think: "a modern piano is a board zither without a resonator," instead of "a modern piano shares some characteristics with other instruments (namely instruments also belonging to the 'board zithers without a resonator family')." We are not able to tell, within this classificatory scheme, what pitch range it is able to produce (when used idiomatically), how many pedals it is equipped with, what its dimensions are, etc. We cannot even link it with its historical predecessor (the historical piano, currently classified in another H-S subcategory) or "descendant" the electric piano (most of the time in an entirely different category).

The integration of the manifold aspects of musical instruments into classification systems would of course result in an important increase in the amount of data. Nevertheless, within a context of the development of the "knowledge societies" (UNESCO 2005), the organization of large quantities of information has become possible. Moreover, rhizome-like systems applied to musical instrument classification could still include taxonomies (namely, inside classes), but would not be limited to this type of organization. It would allow researchers to build a wider conceptual framework for classification, although much less secure than a key. Including a modular approach in the H-S system (even and especially in large digitalization projects such as MIMO that are currently using a revised non-modular version of the H-S classification) would be a first step forward in a process striving for a twenty-first-century way of conceiving musical instruments, as complex - and therefore interesting — objects of investigation.

\section{Acknowledgments}

The authors would like to thank Klaas Coulembier, Rebecca Diependaele, Jeremy Montagu, Don Niles, Frank Parker, and Saskia Willaert for their help and kindness.

\section{REFERENCES CITED}

Aubert, Laurent

1991 “Les outils du musicien: Typologie des instruments de musique." In Mondes en musique, ed. Laurent Aubert, 97-117. Genève: Musée Ethnographique. 
Bakan, Michael B., Wanda Bryant, Guangming Li, David Martinelli, and Kathryn Vaughn 1990 "Demystifying and Classifying Electronic Music Instruments." Selected Reports in Ethnomusicology 8: 37-63.

Berliner, Paul F.

1993 The Soul of Mbira: Music and Traditions of the Shona People of Zimbabwe. 3rd ed. Chicago: University of Chicago Press.

Bertrand, Daniel

1992 Les chevalets "plats" de la lutherie de l'Inde. Paris: Editions de la Maison des sciences de l'homme, coll. Rapports de la Recherche.

Brown, Howard Mayer

1984 "Idiophone." In The New Grove Dictionary of Musical Instruments, ed. Stanley Sadie, vol. 2, 279-80. 3 vols. London: Macmillan.

Dehoux, Vincent

1986 Chants à penser Gbaya (Centrafrique). Paris: Selaf.

Deleuze, Gilles, and Félix Guattari

2009 A Thousand Plateaus: Capitalism and Schizophrenia. Trans. by Brian Massumi. Rev. ed. London: Continuum International Publishing Group.

Fales, Cornelia, and Stephen McAdams

1994 "The Fusion and Layering of Noise and Tone: Implications for Timbre in African Instruments." Leonardo Music Journal 4:69-78.

Fletcher, Neville H., and Thomas D. Rossing

1998 The Physics of Musical Instruments. New York: Springer Verlag.

Galpin, Francis W.

1956 A Textbook of European Musical Instruments: Their Origin, History, and Character. London: Ernest Benn Ltd.

Grame, Theodore C.

1963 Review of "Classification of Music Instruments," by Erich M. von Hornbostel and Curt Sachs, trans. Anthony Baines and Klaus P. Wachsmann (Galpin Society Journal 14, 1961). Ethnomusicology 7/2: 137-38.

Hornbostel, Erich M. von, and Curt Sachs

1961 "Classification of Musical Instruments." Trans. Anthony Baines and Klaus P. Wachsmann. The Galpin Society Journal 14 (March): 3-29. (Translation of: "Systematik der Musikinstrumente: Ein Versuch," Zeitschrift für Ethnologie 46 (1914): 553-90).

Junius, Manfred

1974 The Sitar: The Instrument and its Technique. Whilelmshaven: Heinrichshofen's Verlag.

Kartomi, Margaret J.

1990 On Concepts and Classifications of Musical Instruments. Chicago: University of Chicago Press.

2001 "The Classification of Musical Instruments: Changing Trends in Research from the Late Nineteenth-Century, with Special Reference to the 1990s." Ethnomusicology 45/2: 283-314.

Koenig, Gottfried Michael

1992 Bilthoven 1962/63. III Dezember 1962: Musikalischer Gedanke; serielle Technik; Voraussetzungen der Instrumentalmusik; Klang. Ästhetische Praxis. Texte Zur Musik, Band 2 (1962-67), ed. Wolf Frobenius, Stefan Fricke, Sigrid Konrad, and Roger Pfau. Saarbrücken: Pfau Verlag. 
Kubik, Gerhard

1999 "African and African-American Lamellophones." In Turn up the Volume! A Celebration of African Music, ed. Jacqueline Cogdell DjeDje, 20-57. Los Angeles: UCLA Fowler Museum of Cultural History.

Landrieu, Walter G., and Lucien Goethals

1973 "Electronic Programming of Electro-Acoustical Music." Interface: Journal of New Music Research 2: 71-99.

Leipp, Emile

1989 Acoustique et musique. 4th ed. Paris: Masson.

McKay, Cory, and Ichiro Fujinaga

2005 "Automatic Music Classification and the Importance of Instrument Identification." Proceedings of the Conference on Interdisciplinary Musicology (CIM05), Montreal, Canada, 2005. http://www.oicrm.org/doc/2005/cim05/articles/MCKAY_C_CIM05.pdf.

Merriam, Alan P.

1962 "The African Idiom in Music." Journal of American Folklore 75/296: 120-30. Montagu, Jeremy

1970 "On the Reconstruction of Mediaeval Instruments of Percussion." The Galpin Society Journal 23: 104-14.

2008 "It's Time to Look at Hornbostel-Sachs Again." Paper presented at the 24th European Seminar in Ethnomusicology (ESEM), Warsaw, Poland.

Montagu, Jeremy, and John Burton

1971 “A Proposed New Classification for Musical Instruments." Ethnomusicology 15/1: 49-70.

Niles, Don

1989 “Altérateurs de voix de Papouasie-Nouvelle-Guinée, ou comment la confusion des données appauvrit l'organologie." Cahiers de musiques traditionnelles 2: 75-99.

Quanten, Maarten

2009 "Muzikale Tijd van Reeks tot Algoritme: Temporele strategieën in het werk van Karlheinz Stockhausen en Gottfried Michael Koenig (1952-1966).” PhD dissertation, Katholieke Universiteit Leuven.

Rossing, Thomas D., Ingolf Bork, Huan Zhao, and Dell O. Fystrom

1992 "Acoustics of Snare Drums." Journal of the Acoustical Society of America 92/1: 84-94.

Sachs, Curt

1940 The History of Musical Instruments. New York: W. W. Norton and Co.

Tracey, Hugh

1948 Handbook for Librarians. Roodeport: African Music Society.

UNESCO

2005 Towards Knowledge Societies. UNESCO World Report. Paris: UNESCO

Publishing. http://unesdoc.unesco.org/images/0014/001418/141843e.pdf.

Weisser, Stéphanie

2005 "Etude ethnomusicologique du bagana, lyre d'Ethiopie." PhD dissertation, Université Libre de Bruxelles. 


\section{Appendix: A proposed subdivision of the fifth category of the H-S classification system}

Quanten created a high-level differentiation between modules and configurations so as to serve the goal of a modular approach to the H-S taxonomy. This subdivision is kept short, as within this context it serves only the goal of exemplifying a possible codification of the composite nature of electronic instruments. More subdivisions could be made. A different version (without the modular approach) was developed by Tim Boon and Quanten, and is currently being used by MIMO as a fifth category of the revised H-S scheme.

\section{Electrophones}

51 Analogue electronic modules/components: devices containing electronic circuitry, designed to produce or process electronic audio signals or to control other devices (control voltages).

\section{Audio signal generators}

511.1 sine and/or sawtooth- and/or rectangular- and/or triangular- and/or squarewave generators

511.2 white- and coloured-noise generators

\section{Signal modifiers}

512.1 spectrum modifiers (filters)

512.11 high-pass filter

512.12 low-pass filter

512.13 band-pass filter

512.14 band-reject/notch and comb filters

512.15 multimode filter

512.2 amplitude modifiers (amplifiers)

512.3 reverberation modifiers

\section{Signal-combining devices}

513.1 mixers

$513.2 \mathrm{sum} /$ difference/multiple output signal generators (e.g., ring modulators)

\section{Voltage control sources}

514.1 generators of voltage control sequences (e.g., envelope generator, LFO, sequencer)

514.11 LFO

514.12 envelope generator

514.13 sequencer

514.14 sample and hold

514.15 random voltage generator

514.16 envelope detector/envelope follower/peak amplitude follower

514.17 slew generator

514.18 slew limiter

514.2 controllers and interfaces

514.21 keyboard

\section{Transducers}

515.1 air microphones

515.2 contact microphones

515.3 pick-ups

516 Modules communicating between devices/signal converters other than transducers

516.1 pitch-to-control voltage converter 
52 Analogue electronic configurations devices containing several modules from 51 and forming a specific assemblage

521 Electro-acoustic instruments: configurations of acoustic, vibratory mechanisms (often resembling traditional acoustic instruments) and electronic circuitry, such as transducers (pick-ups), amplifiers, and speakers. The acoustic or mechanical vibration is transduced into an analogue fluctuation of an electric current.

521.1 electro-acoustic idiophone

521.2 electro-acoustic membranophone

521.3 electro-acoustic chordophone

521.4 electro-acoustic aerophone

522 Electromechanical instruments and devices: Electromechanical instruments: configurations of (electrically excited) silent, mechanical moving parts with encoded patterns, and electronic circuitry. The movement enables the encoded patterns to be transduced into an analogue fluctuation of an electric current.

522.1 tonewheel instruments (electromagnetic, electrostatic, photoelectric, etc.)

522.2 photoelectric electromechanical instruments

$522.3 \mathrm{record} /$ playback devices (electromechanical, electromagnetic, etc.)

522.4 electromechanical samplers

522.5 electromechanical sound processing devices

523 Analogue electronic instruments, modules and components: configurations containing analogue fully electronic devices used to produce, process, and communicate electronic sound signals and/or sequences of signals.

523.1 analogue synthesizers/vocoder and transistor, valve or analogue integrated circuit instruments

523.2 sequencer-based designs

523.3 signal mixer console

523.4 amplifier (e.g., with filters)

523.5 other configurations, experimental designs, sound sculptures, installations 